\title{
Good-Bye Old Friends
}

Sigmund Weissmann and Ben Post were more than outstanding scientists and Editors of the Powder Diffraction File (PDF); they were good friends to everyone in the field. They will be missed by all of us who have known them and worked with them over the years especially in the International Centre for Diffraction Data on the PDF where they devoted so much of their professional activities for over 30 years. This issue of Powder Diffraction is dedicated to their memory. An article based on an interview with Ben Post by Richard Rose was published previously [Powder Diffr. 8, 131-136 (1990)]. A similar article on Sigmund Weissmann is included in this issue along with the last paper prepared to describe his latest project activities in the International Centre for Diffraction Data (ICDD).

I cannot remember the first time I met Ben, but it must have been at an early meeting of the American Crystallographic Association. Ben's wit and humor would attract any young student, but what would be remembered most was the warm approach he had toward new members, making them feel welcome in the august body of well-known scientists. It was through Ben and others like him that I was instilled with the fun and significance of crystallography as a science and a career. We had many debates over the years on scientific matters, and he was always helpful, especially in the theoretical understanding of the experimental information.

Ben approached new ideas with caution. He did not jump to fast conclusions, but weighed all the evidence prior to accepting new suggestions and interpretations of scientific data. When I first introduced the calculated diffraction pattern to ICDD, he was reluctant to accept its usefulness in powder data interpretation. After his own testing and evaluation, he became a strong supporter of such structure modeling. Ben was of the school where intuition was as important as calculation in the analysis of scientific data.

I do remember my first meeting with Sig. I was beginning to expand my studies into defects in crystals and was looking to set up new equipment in the diffraction facility at the Lawrence Livermore National Laboratory in the early 1960s. I had heard that Sig was the expert in this field, so I called him and arranged to visit his lab in New Jersey on my next trip. The November day of my visit was so foggy that I was lucky to find my way. After I arrived, however, the fog cleared, and Sig was extremely helpful. He subsequently worked with me as a consultant on my project. In addition, it was Sig who sponsored my early entrance into the activities of ICDD.

For many of us, fond memories of Sig are at the piano where he was an accomplished concert musician. His many recitals at scientific meetings and impromptu sessions entertained us for many hours. The piano for Sig was more than relaxation; it was a form of expression into which he added feeling as well as function.

For the last 15 years, the ICDD has been considering the time when Ben and Sig would have to be replaced as Editors of the PDF. Their knowledge and experience were so valuable that little effort to find new Editors was made until only a few years ago. Fortunately, the transition to the new Editors has had the benefit of overlap with the masters. In addition to the editorial insight applied by these Editors in the days before computers were applied to pattern evaluations, both Ben and Sig contributed many suggestions to the development of the NBS *AIDS editorial program on which modern pattern evaluations now rely.

This editorial would not be complete without mentioning two other ICDD associates who have passed away this year also, Boris Paretzkin and V. A. Frank-Kamanetsky. Boris Paretzkin was a member of the ICDD Associateship at the National Institute for Standards and Technology for many years. He was an author of the NBS Monograph 25, which produced so many good powder patterns for the PDF. He also translated Russian articles for the ICDD. Boris was an early student of Ben Post. Professor V. A. Frank-Kamanetsky was a member of the Editorial Board of Powder Diffraction from its founding. Primarily through the efforts of J. D. Hanawalt, he was the principal contact of the ICDD in Russia during and after the cold war era and contributed many patterns to the PDF over the years. This association has subsequently resulted in additional projects in Russia which are supported by ICDD.

This year, 1994, has not been a good year for crystallographers with so many notables passing away. Regardless, the many contributions and innovations produced by these individuals will certainly carry on in the students and associates of our parted friends.

Deane K. Smith Editor-in-Chief 